\title{
Modeling environmental bias and computing velocity field from data of Terra Nova Bay GPS network in Antarctica by means of a quasi-observation processing approach
}

\author{
Giuseppe Casula, ${ }^{1}$ Marco Dubbini, ${ }^{2}$ and Angelo Galeandro ${ }^{3}$ \\ ${ }^{1}$ Istituto Nazionale di Geofisica e Vulcanologia, Centro Nazionale Terremoti, Sezione di Bologna, Via Donato Creti 12 - 40128 Bologna, Italy \\ (casula@bo.ingv.it) \\ ${ }^{2}$ DIMeC, Università di Modena e Reggio dell'Emilia, Via Vignolese 905 - 41100 Modena, Italy (marco.dubbini@unimore.it) \\ ${ }^{3}$ Politecnico di Bari, Viale del Turismo, 8-74100 Taranto, Italy (agaleandro@gmail.com)
}

\begin{abstract}
A semi-permanent GPS network of about 30 vertices has been installed at Terra Nova Bay (TNB) near Ross Sea in Antarctica. A permanent GPS station TNB1 based on an Ashtech Z-XII dual frequency P-code GPS receiver with ASH700936D_M Choke Ring Antenna has been mounted on a reinforced concrete pillar built on bedrock since October 1998 and has recorded continuously up to the present. The semi-permanent network has been routinely surveyed every summer using high quality dual frequency GPS receivers with 24 hour sessions at 15 sec rate; data, metadata and solutions will be available to the scientific community at (http://www.geodant.unimore.it). We present the results of a distributed session approach applied to processing GPS data of the TNB GPS network, and based on Gamit/Globk 10.2-3 GPS analysis software. The results are in good agreement with other authors' computations and with many of the theoretical models.

Citation: Casula, G., M. Dubbini, and A. Galeandro (2007), Modeling environmental bias and computing velocity field from data of Terra Nova Bay GPS network in Antarctica by means of a quasi-observation processing approach, in Antarctica: A Keystone in a Changing World - Online Proceeding of the $10^{\text {th }}$ ISAES, edited by A. K. Cooper and C. R. Raymond et al., USGS Open-File Report 2007-1047, Short Research Paper 054, 4 p.; doi: 10.3133/of2007-1047.srp054
\end{abstract}

\section{Introduction}

During the last years, the rapid development of the GNSS/GPS system has provided more precise satellite orbital parameters, through the enlargement of the GPS satellite constellation, and the improvement of the global continuous GPS (CGPS) tracking network (Serpelloni et al., 2006). Moreover, the establishment of regional permanent and semi-permanent networks of GPS stations has increased the number of stations available to tie observations together. In addition, the quality of data from modern dual frequency receivers was improved through adding several technological facilities. For these reasons GPS technology was deployed in North Victoria Land, East Antarctica. Starting from 1998, a geodetic infrastructure was installed in the area of Terra Nova Bay: the permanent station of TNB1 installed at Mario Zucchelli station, and the GPS semi-permanent network of North Victoria Land (VLNDEF) specifically designed with the aim of measuring the crustal deformation of the region (Capra et al., 2004, 2007).

In this paper we describe VLNDEF GPS data processing that, starting from a distributed session approach and by means of Gamit/Globk 10.2-3 (Herring et al., 2006a,b) software, with the aid of a regional clustering setup, has enabled us to compute the ITRF2000 velocities of the VLNDEF sites. In addition, the derivation of a stable reference frame for the Antarctic plate has enabled the computation of site by site residual intra-plate velocities.

\section{Data analysis and results}

We used the Gamit/Globk 10.2-3 GPS analysis software (Herring et al., 2006a,b) and a quasi-observation

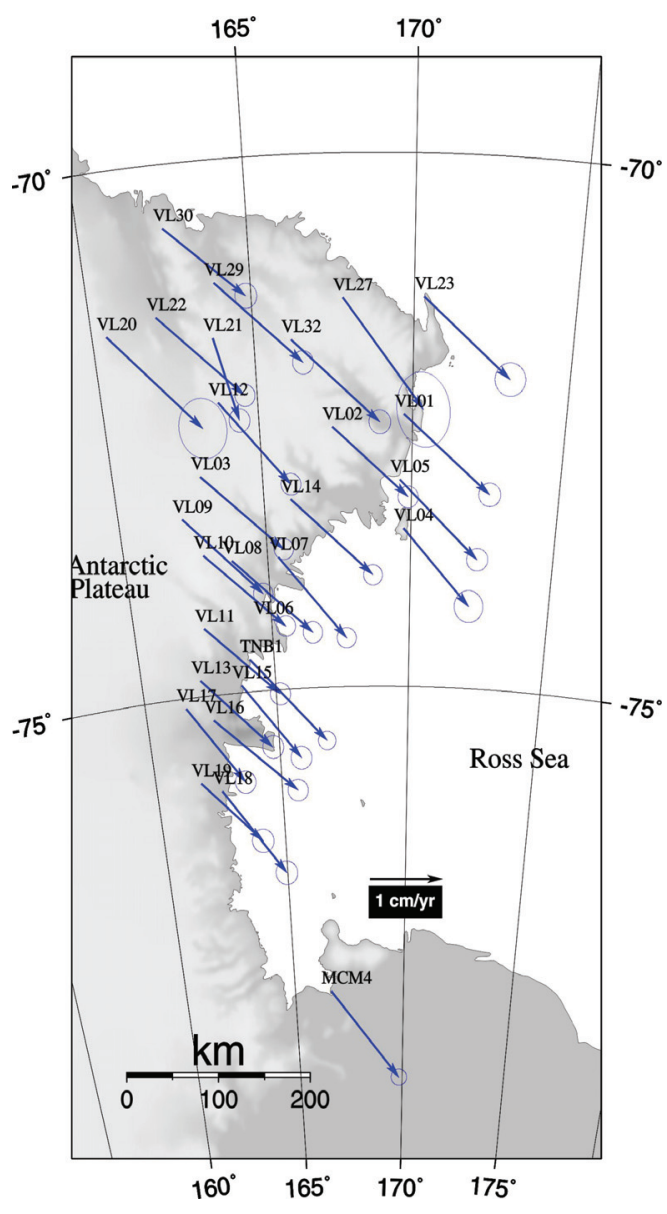

Figure 1. ITRF2000 horizontal velocity field of VLNDEF GPS Network sites. 
multi step procedure, to compute the residual velocity field for the network of GPS stations in a stable reference frame for the Antarctic plate. At the beginning of our procedure we computed the initial solutions starting from the observed GPS phase and codes. In particular, we computed loosely constrained daily solutions (h-files) simultaneously with the estimates of coordinates, satellite orbital parameters, atmospheric corrections, integer-cycle ambiguities and variance-covariance matrices using the doubly differenced GPS phase observations for every site measured (Serpelloni et al. 2006). In the second step, quasi-observation data were combined with the solutions (h-files) downloaded from facility (ftp://lox.ucsd.edu/pub/hfiles) taking into account the value of the Chi-squared indicator, as a criterion to estimate the goodness of fit of the model (Dong et al., 1998; Serpelloni et al., 2006).

In the third step, an ITRF2000 reference frame velocity field for all sites of the VLNDEF network was obtained by applying position and velocity constraints (stabilisation), to some of the IGS-GNSS global permanent network sites included in the computation, see Figure 1. The error ellipses of the absolute velocities were computed at $95 \%$ confidence level taking into account the white noise and coloured noise components that always affect the GPS sites position time series (Mao et al. 1999).

Data were edited by means of tsview matlab-tools (Herring 2003) in order to estimate, by means of least square robust fit, outliers, offsets, and time series common noise modes like seasonal annual and semi- annual components. A final GLOBK run was applied to the overall data-set in order to estimate, by means of sequential Kalman filtering, the velocities in the ITRF2000 (Altamini et al. 2002) reference frame. Activation of a site by site random-walk processes ( $\left.\mathrm{mar}_{\mathrm{N}} \mathrm{neu}\right)$ in the Kalman filtering procedure was done in order to add a correct amount of coloured pink and red noise to the estimated VLNDEF sites velocity error ellipses (Herring et al., 2006b).

In the final step the rigid Antarctic plate rotation was removed from ITRF2000 sites velocities by means of the general definition of Absolute Euler Vector (Altamini et al. 2002), relating the Antarctic plate to the Pacific plate. This procedure gives us the VLNDEF sites residual velocity field in a well defined Antarctic plate (Figures 2 and 3). As observed in Figure 2, the goodness of our definition of an Antarctic reference plate can be assessed by the fact that the horizontal components of the residual velocities of the eight Antarctic sites used to define the plate are always at the level of $1 \mathrm{~mm} / \mathrm{yr}$ or less. As pointed out by other authors (Nakada, et al. 2000, Dietrich et al. 2004, Donnellan and Luyendyk, 2004, Ohzono et al., 2006) and as can be observed in Figure 2 and Figure 3 , the Antarctic plate behaves as a rigid block with internal strain rates which are at the level of $10^{-9} / \mathrm{yr}$ or less. In fact all the residual velocities of our solution are closely comparable with their error ellipses (we estimated 1-2 $\mathrm{mm} / \mathrm{yr}$ of white and coloured noise). The vertical component of the velocity field, even if characterised by $2-5 \mathrm{~mm} / \mathrm{yr}$ white plus coloured noise, show almost

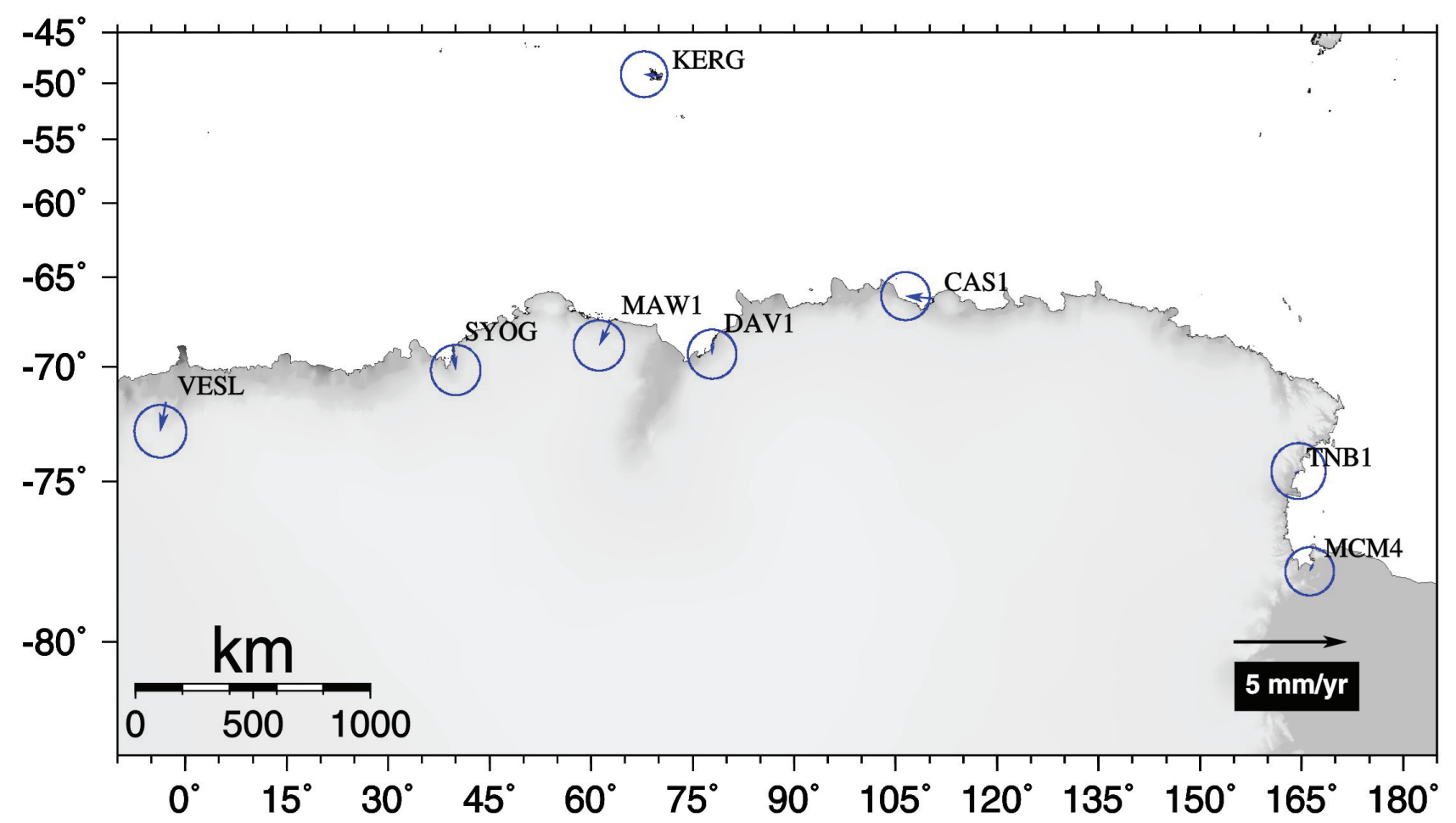

Figure 2. Horizontal residual velocities of the eight Antarctic sites chosen to define the plate. 


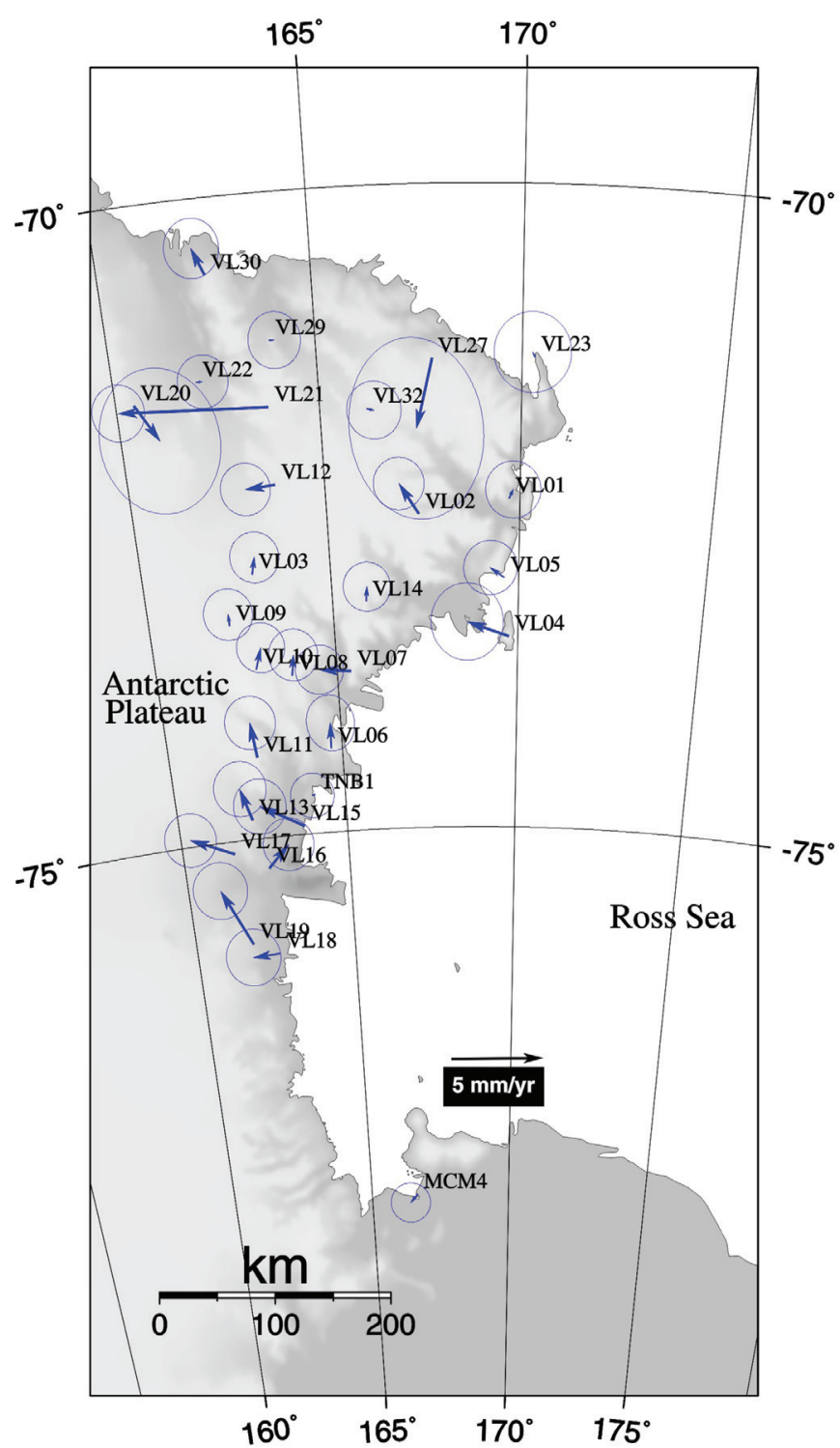

Figure 3. Residual horizontal velocities together with their error ellipses at $95 \%$ confidence level of VLNDEF GPS network in Antarctic plate reference frame as defined in this work.

everywhere a positive trend of 2-3 mm/yr. Although, owing to the high level of noise, this result is characterised by a low significance it is in agreement with the theoretical computation of the vertical uplift given by Ivins et al. (2003).

\section{Discussion and conclusions}

A distributed session approach based on Gamit/Globk 10.2-3 software package has been applied to VLNDEF (Victoria Land Network) GPS data in order to compute ITRF2000 velocities for all the sites and residual intraplate velocities (see Figure 2-3). A robust definition of the Antarctic plate reference frame was obtained using eight GPS permanent stations in the continent characterised by horizontal residual velocities little than $1 \mathrm{~mm} / \mathrm{yr}$. The

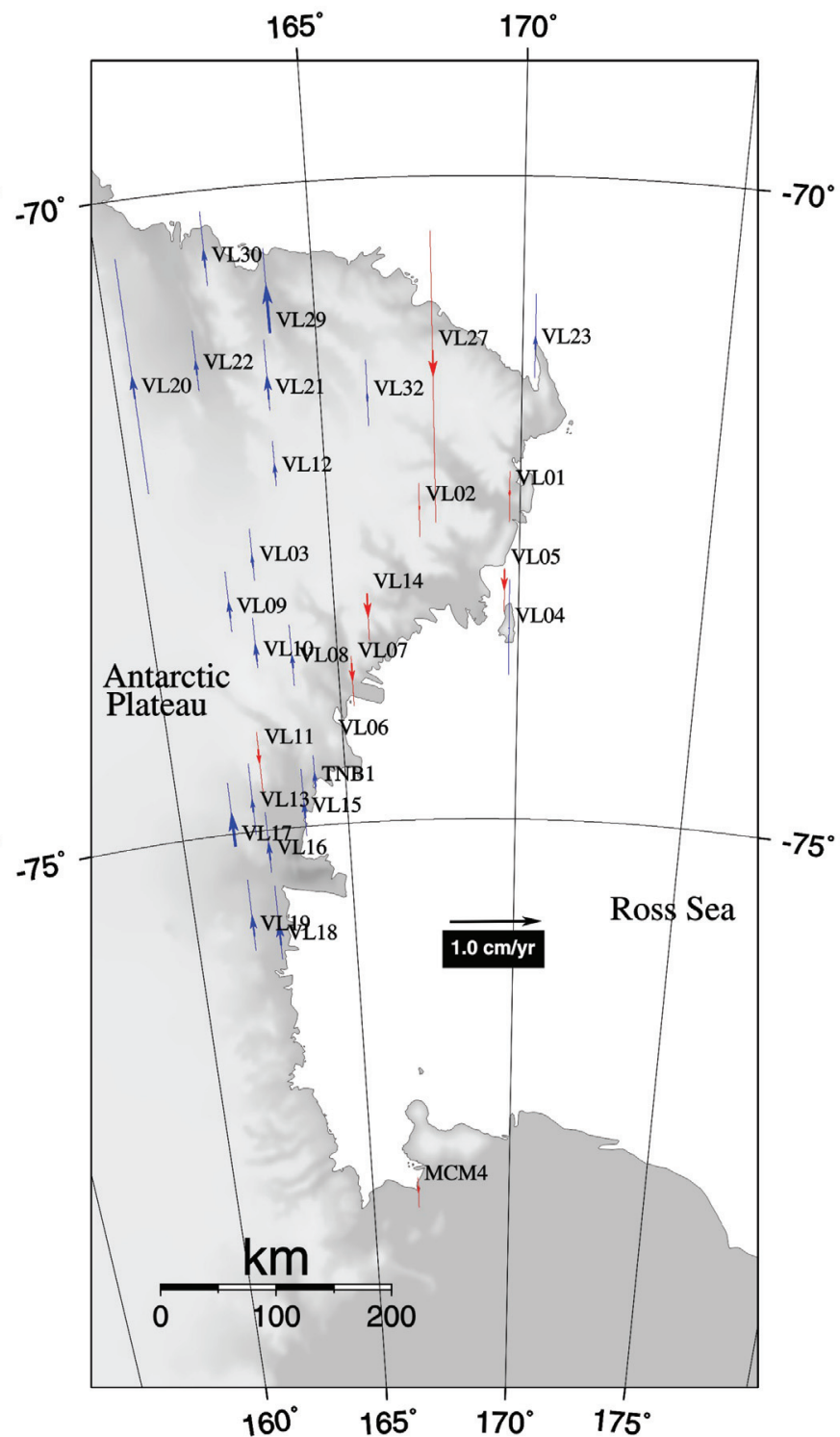

Figure 4. VLNDEF GPS network sites vertical velocities.

residual intra-plate horizontal velocities of all VLNDEF sites are almost everywhere between 1-2 $\mathrm{mm} / \mathrm{yr}$ confirming that the Antarctic plate behaves uniformly as a rigid plate, and are in agreement with the horizontal velocities predicted by the majority of theoretical models (Nakada et al. 2000, Ohzono et al. 2006). On the contrary, the sites VL27 and VL21 shows a different behaviour, the VL27 one has only two determinations available explaining the large error-ellipse and deviation, meanwhile the residual velocity of site VL21 shows 1 $\mathrm{cm} / \mathrm{yr}$ or more eastward horizontal motion which need to be more investigated and is probably due to monument instability. The vertical velocity field shown in Figure 4 is characterised almost everywhere by a vertical trend between 1-2 $\mathrm{mm} / \mathrm{yr}$ but is affected by a vertical noise of 4-5 $\mathrm{mm} / \mathrm{yr}$ or more, reducing the significance of this latter 
result. In any case, this trend, where positive, is consistent with the model of vertical deformation given by Ivins et al. 2003.

Acknowledgements. All researches were carried out in the framework of the Programma Nazionale di Ricerche in Antartide and financially supported by PRNA S.C.r.1.. The figures of this paper were produced by means of Generic Mapping Tools (GMT) graphic package (Wessel and Smith, 1998). Reviews by F. Davey, T.A. Herring and K. Shibuya really contribute to improve the manuscript.

\section{References}

Altamini, Z., P. Sillard, and C. Boucher (2002), ITRF2000 A new release of the International Terrestrial Reference Frame for Earth Science Applications. Journal of Geophysical Research, Vol. 107, B10, 2214, 2-19. 10.1029/2001JB00056.

Capra, A., S. Gandolfi, F. Mancini, M. Negusini, P. Sarti, and L. Vittuari (2004), Terra Nova Bay GPS permanent station. In Brancolini, G., Ghezzo, C. \& Morelli, A., eds. Terra Antartica Reports, 9, 21-24.

Capra, A.., F. Mancini, and M. Negusini (2007), GPS a geodetic tool for geodynamics in northern Victoria Land, Antarctica, Antarctic Science, 19(1), 107-114.

Dietrich, R., A. Rülke, J. Ihde, K. Lindner, H. Miller, W. Niemeier, H.W. Schenke, and G. Seeber (2004), Plate kinematics and deformation status of the Antarctic Peninsula based on GPS. Global and Planetary Change, 42(1-4), 313-321.

Dong, D.N., T.A. Herring, and R.W. King (1998), Estimating regional deformation from a combination of space and terrestrial geodetic data, Journal of Geodesy, 72, 200-214.

Donnellan, A., and B.P Luyendyk (2004), GPS evidence for a coherent Antarctic plate and for postglacial rebound in Marie Byrd Land. Global and Planetary Change, Vol. 42, pp. 305-311.

Herring, T.A. (2003), MATLAB Tools for viewing GPS velocities and time series. GPS Solutions, Vol. 7, Num. 3, pag. 194-199.

Herring, T. A., R. W King, and S. C. McClusky (2006a), GPS Analysis at MIT, Gamit Reference Manual, Release 10.3, Department of Earth, Atmospheric, and Planetary Sciences Massachussetts Institute of Technology, Cambridge.

Herring, T.A., R.W. King, and S.C. McClusky (2006b), Global Kalman filter VLBI and GPS analysis program, Globk Reference Manual, Release 10.3. Department of Earth, Atmospheric, and Planetary Sciences Massachussetts Institute of Technology, Cambridge.

Ivins, E.R., T.S. James, and V. Klemann (2003), Glacial isostatic stress shadowing by the Antarctic ice sheet. Journal of Geophysical Research, Vol. 108, B12, pp 2560 doi:10.129/2002JB002182.

Mao, A., G. Cristopher, A. Harrison, and T. H. Dixon (1999), Noise in GPS coordinate time series, Journal of Geophysical Research, Vol. 104, No. B4, 2797-2816.

Nakada M., R. Kimura, J Okuno, K. Moriwaki., H Miura, and H. Maemoku (2000), Late Pleistocene and Holocene melting history of the Antarctic ice sheet derived from sea-level variations. Marine Geology, Vol. 167, pp. 85-103.

Ohzono M., T. Tabei, K. Doi, K. Shibuya, and T. Sagiya (2006), Crustal movement of Antarctica and Syowa Station based on GPS measurements. Earth Planets Space, Vol. 58, pp. 795-804.

Serpelloni E., G. Casula, A. Galvani, M. Anzidei, and P. Baldi (2006), Data analysis of permanent GPS networks in Italy and surrounding regions: applications of a distributed processing approach. Annals of Geophysics. VOL. 49, N 4/5, August/October 2006.

Wessel, P., and W.H.F. Smith (1998), New, Improved Version of Generic Mapping Tools Released, EOS Trans. AGU, 79 (47), 579. 